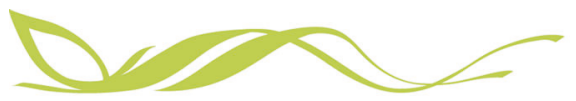

COMMUNICATIONS

EARTH\&ENMRONMENT

ARTICLE

https://doi.org/10.1038/s43247-020-00086-3 OPEN

\title{
Conjugate faulting and structural complexity on the young fault system associated with the 2000 Tottori earthquake
}

Aitaro Kato (id ${ }^{1 凶}$, Shin'ichi Sakai ${ }^{1,2}$, Satoshi Matsumoto ${ }^{3} \&$ Yoshihisa lio (i) ${ }^{4}$

Young faults display unique complexity associated with their evolution, but how this relates to earthquake occurrence is unclear. Unravelling the fine-scale complexity in these systems could lead to a greater understanding of ongoing strain localization in young fault zones. Here we present high-spatial-resolution images of seismic sources and structural properties along a young fault zone that hosted the Tottori earthquake ( $M w 6.8$ ) in southwest Japan in 2000, based on data from a hyperdense network of $\sim 1,000$ seismic stations. Our precise microearthquake catalog reveals conjugate faulting over multiple length scales. These conjugate faults are well developed in zones of low seismic velocity. A vertically dipping seismic cluster of about $200 \mathrm{~m}$ length occurs within a width of about $10 \mathrm{~m}$. Earthquake migrations in this cluster have a speed of about $30 \mathrm{~m}$ per day, which suggests that fluid diffusion plays a role. We suggest that fine structural complexities influence the pattern of seismicity in a developing fault system.

\footnotetext{
${ }^{1}$ Earthquake Research Institute, The University of Tokyo, 1-1-1 Yayoi, Bunkyo-ku, Tokyo 113-0032, Japan. ${ }^{2}$ Interfaculty Initiative in Information Studies, The University of Tokyo, 7-3-1 Hongo, Bunkyo-ku, Tokyo 113-0033, Japan. ${ }^{3}$ Institute of Seismology and Volcanology, Kyushu University, 744 Moto-oka, Nishi-ku, Fukuoka 819-0395, Japan. ${ }^{4}$ Disaster Prevention Research Institute, Kyoto University, Gokasho, Uji, Kyoto 611-0011, Japan. ${ }^{凶}$ email: akato@eri.u-tokyo.ac.jp
} 
F ault systems develop with an increase in total fault displacement. During the initial stage of development, tectonic strain is accommodated by pervasive brittle deformation that can be associated with discontinuities such as bends, stepovers, and conjugate faults ${ }^{1}$. However, as the total displacement increases, slip gradually localizes into one major smooth fault ${ }^{2}$, eventually resulting to a release of tectonic strain along it. In a young fault system, fault geometries, and structural properties are likely to change in a complex manner. Complicate interactions between discontinuous faults and lateral structural properties may promote or inhibit fault nucleation and growth, and produce fault linkage and coalescence ${ }^{1}$. In addition, these interactions can control spatio-temporal pattern of seismic activity, slip distribution, and the location of large earthquake rupture areas, which are important in seismic hazard assessment ${ }^{3,4}$. Recent seismic and geodetic observations of fault networks have revealed that multiple ruptures along conjugate and subparallel faults can occur simultaneously or in quick succession $^{4-8}$. Crustal fluids spreading through a fault network can also enhance fault-slip ${ }^{9-12}$. However, fault complexity along young fault systems is poorly understood owing to a lack of highspatial resolution images of seismic sources and structural properties at seismogenic depths.

To address this issue, we deployed a spatially dense seismic array of 1000 vertical short-period sensors in and around the source area of the 2000 Tottori earthquake (Japan Meteorological Agency (JMA) magnitude Mj 7.3; $\mathrm{Mw}$ 6.8), and obtained continuous waveform data from April 2017 to April 2018 (13 months) (Fig. 1). The Tottori earthquake took place along a left-lateral strike-slip fault within the San-in active shear zone, which is characterized by a high seismicity rate and a large shear strain rate of $1.0 \times 10^{-7} /$ year $^{13-15}$. Along the San-in shear zone, a conjugate seismic lineation with WSW-ENE and NNW-SSE trends can be recognized from the JMA catalog (Fig. 1a). A Global Navigation Satellite System network has revealed that the shear deformation zone is as wide as $50 \mathrm{~km}$ along the seismic belt $^{15}$. However, no major active faults have been identified at the surface in the San-in region (Fig. 1a). A detailed geomorphological study has clarified that conjugate active faults with WSW-ENE and NNW-SSE trends are distributed within the San-in shear zone, but that they are young growing faults with cumulative offsets of less than a few hundreds of meters ${ }^{16}$. Indeed, no obvious surface traces of active faults linked to the 2000 Tottori earthquake have been identified (Fig. 2a), indicating that a major fault structure has not developed in the study area. These observations suggest that the San-in shear zone is a young fault system with many faults that lie parallel and oblique to the shear zone $e^{15}$, but there is little constraint on the small-scale structures within the shear zone.

The average spatial interval of the hyperdense seismic network used in this study is $\sim 1 \mathrm{~km}$, covering the entire aftershock area within a radius of $\sim 15 \mathrm{~km}$ (Fig. 1b). High-density seismic arrays have been deployed in other tectonic environments, but the network used in this study is the first high-density seismic array
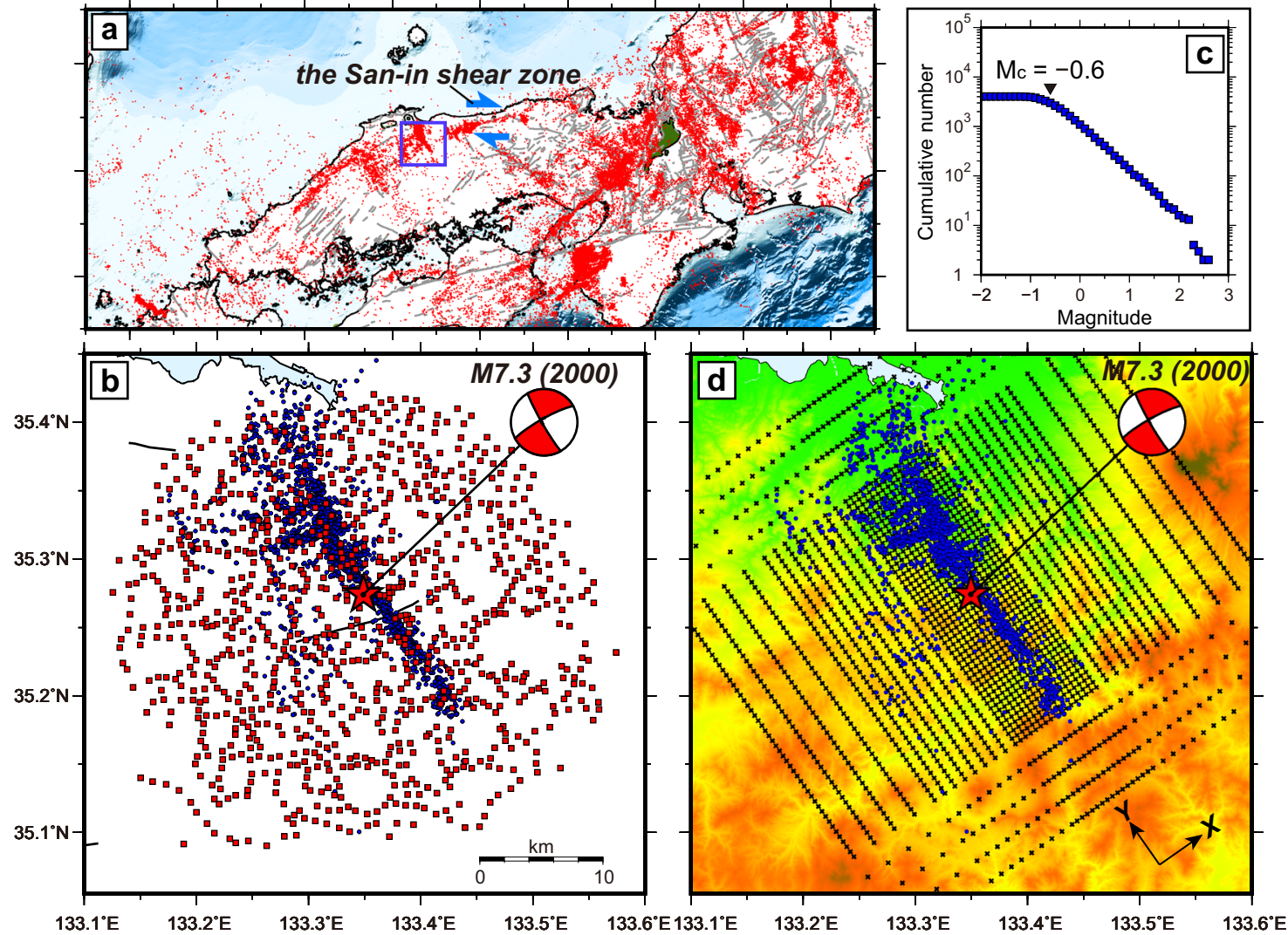

Fig. 1 Tectonic setting and hyperdense seismic network. a Map of seismicity and surface traces of active faults (gray lines) in and around the San-in shear zone, SW Japan. The shear zone is characterized by a high seismicity rate and a large right-lateral shear strain rate. Blue rectangle denotes the location of (b). b Locations of seismic stations (red squares) in the hyperdense network and the relocated earthquakes (blue circles). Red star denotes the epicenter of the 2000 Tottori earthquake determined by JMA with CMT solution determined by the National Research Institute for Earth Science and Disaster Resilience (NIED). Black line is the surface trace of an active fault. c Plot of cumulative number of analyzed earthquakes as a function of magnitude. $\mathbf{d}$ Map of the grid used in the tomography analysis (crosses) and the relocated earthquakes (blue circles), overlaid on top of the terrain. The horizontal grid spacing near the mainshock fault plane is $0.5 \mathrm{~km}$. 


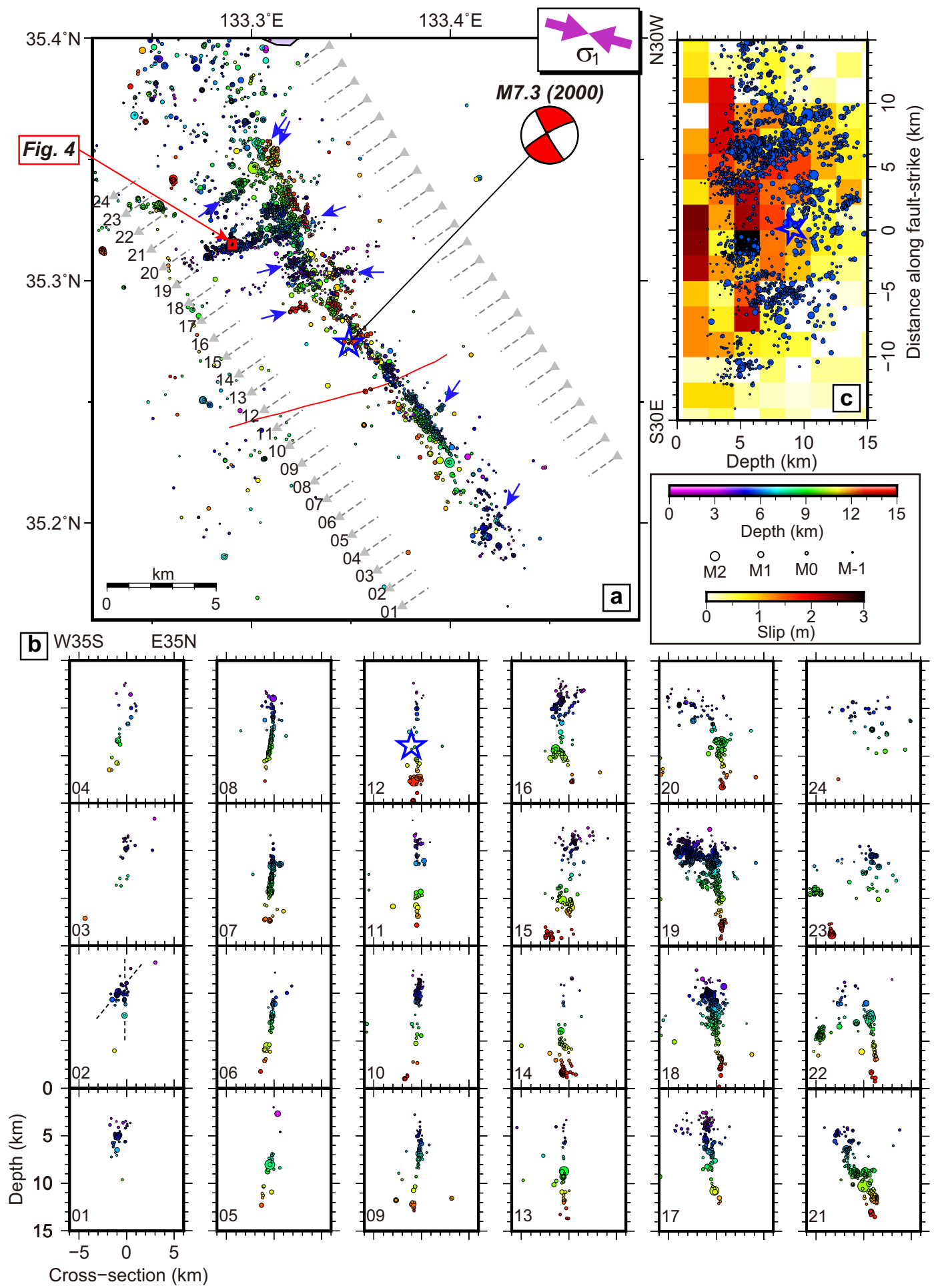

Fig. 2 Map and cross-sectional views of persisting aftershocks. a Epicentral map of the relocated hypocenters, which are shown as circles that are scaled to earthquake magnitude and colored to hypocentral depth. Blue star denotes the epicenter of the 2000 Tottori earthquake. Each blue arrow indicates conjugate vertical lineation. A small red rectangle around the slice 19 denotes a tiny seismic cluster in Fig. 4. Purple arrows in the inset show the orientation of the maximum compressive stress $\left(\sigma_{1}\right)^{14}$. Red line is the surface trace of an active fault. $\mathbf{b}$ Depth sections of the relocated hypocenters along the profiles shown in (a). c Seismicity cross-section for events within $2.5 \mathrm{~km}$ of a profile along the mainshock fault plane (blue circles). Background color denotes the coseismic-slip distribution of the 2000 Tottori earthquake inverted using strong motion waveforms and GPS data ${ }^{27}$.

to be installed for more than 1 year, and above the aftershock area of a magnitude $\sim 7$ earthquake ${ }^{17,18}$, to the best of our knowledge. Using the waveform data retrieved from the hyperdense network, we obtained arrival time data for 4033 micro-earthquakes with magnitudes greater than the completeness magnitude of $M_{\mathrm{L}}-0.6$
(Fig. 1c). Dense, well-covered ray-paths from the many sources provide valuable opportunities to (1) precisely map the aftershock distribution following the 2000 Tottori earthquake (Fig. 1d), (2) delineate fine-scale $\mathrm{P}$-wave velocity structures with a spatial resolution down to $500 \mathrm{~m},(3)$ explore the spatial and temporal 
evolution of a small seismic cluster, and (4) understand the multiscale complexity of this young fault system at depth.

\section{Results}

Geometric complexity of faults and velocity structures. Nearly 20 years have passed since the 2000 Tottori earthquake, but the relocated hypocenters clearly reflect complex fault structures that extend along a dominantly NW-SE trend in the source area (Fig. 2a). The relocated seismicity shows that the seismogenic zone extends down to $15 \mathrm{~km}$ depth, gradually decreasing to $\sim 5 \mathrm{~km}$ depth toward the tips of the fault (Fig. 2b, c). This pattern of detected seismicity is similar to that of aftershocks that immediately followed the mainshock rupture ${ }^{14,19}$. This means that micro-seismicity (down to negative magnitudes) can be used to reconstruct geometric complexities produced by the mainshock rupture, even after $\sim 20$ years. The JMA catalog shows a similar spatial pattern of seismicity (Supplementary Fig. S1), but the geometric complexity (the cross-section numbers from 15 to 23 in Fig. 2a) is poorly defined due to the sparse coverage of the nationwide online seismic network.

Near the initiation point of the mainshock rupture, most events are well-aligned along a steeply dipping fault that strikes N35W-S35E (Fig. 2b). Near the mainshock epicenter, the major ruptured area is characterized as a high-velocity body (Fig. 3 and Supplementary Figs. S2-S6). Within the major ruptured area, aftershocks are notably less common (Figs. 2c and 3). This is a common feature in the largeslip regions of many other earthquakes ${ }^{20,21}$.
In contrast, many relocated events on the northwest side of the source area have conjugate vertical alignments (blue arrows in Fig. 2a). The data show that the fault zone exhibits conjugate faulting over multiple length scales. The most prominent conjugate fault plane extends toward W20S from the main trend, with a horizontal length of $\sim 5 \mathrm{~km}$ along strike. This prominent aftershock lineation occurs close to the distinct boundary between a low-velocity body and a high-velocity body, on the northwestern side of the mainshock epicenter (Fig. 3 and Supplementary Figs. S2-S6). The boundary between the lowand high-velocity bodies trends W20S-E20N, and the observed seismicity rate is higher along this boundary than in other areas. The magnitude of the velocity contrast between the NNW and SSE sides of this boundary increases from deep to shallow depths (Fig. 3). As discussed in previous studies ${ }^{19,22}$, the shallow remarkable low-velocity body might be composed primarily of non-alkali volcanic and pyroclastic rocks of the early to middle Miocene. However, the present model shows that the velocity contrast extends down to greater depths. The high-velocity body might be interpreted to be plutonic and metamorphic rocks from surface geological map.

Toward the southeastern edge of the fault zone, the relocated aftershocks begin to change dip slightly with depth. The aftershock orientations become listric, transitioning to a dip of $\sim 75^{\circ}$ toward W35S at a depth of around $8 \mathrm{~km}$ (slices $04-10$ in Fig. 2b). This dipping direction is opposite to the aftershock orientations dipping $\sim 75^{\circ}$ toward E35N observed on the northwest side of the source area (slices $17-21$ in Fig. $2 b$ ). We also
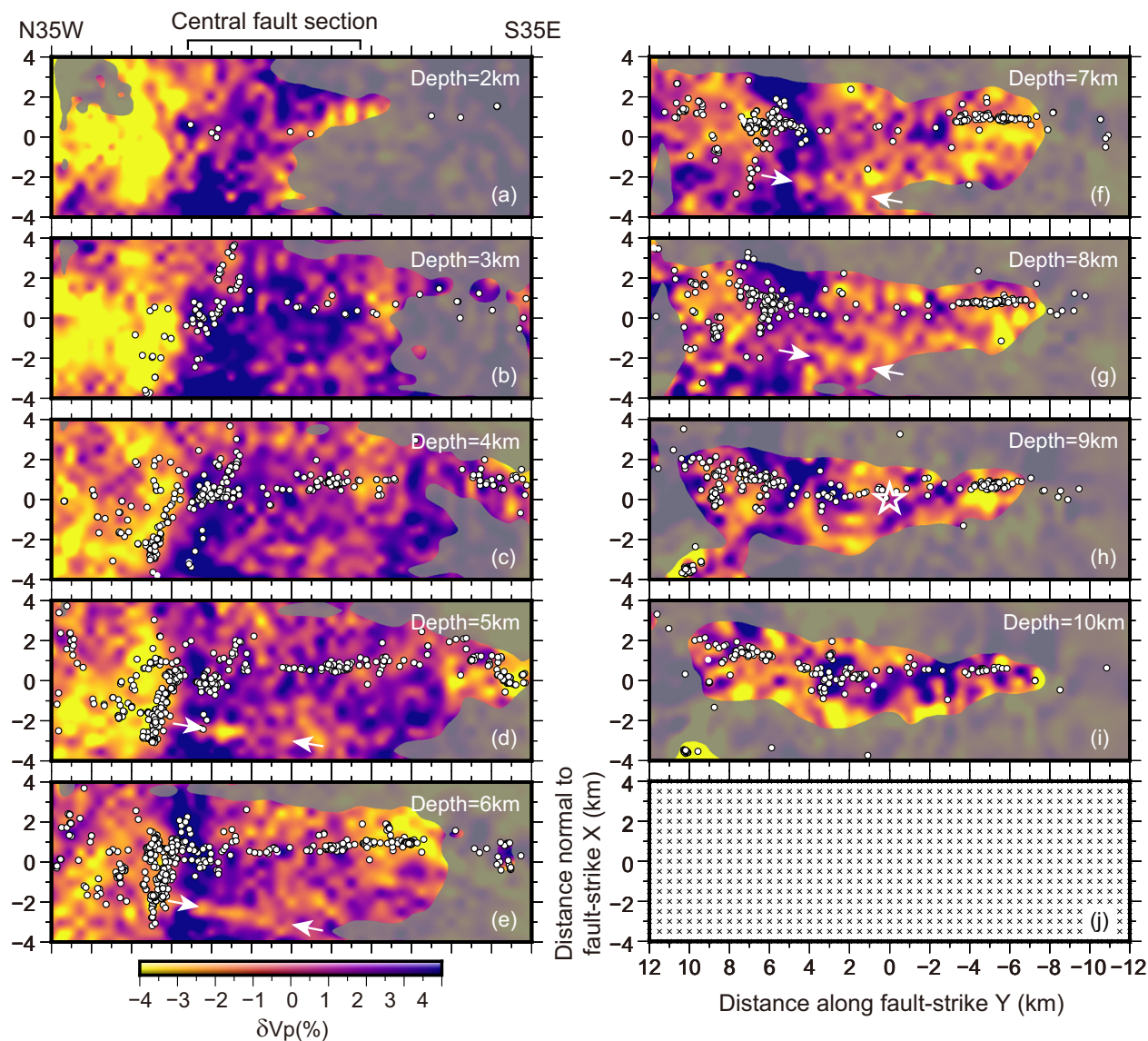

Fig. 3 P-wave velocity perturbation along the $\mathbf{2 0 0 0}$ Tottori earthquake at each depth. P-wave velocity perturbation rotated along the major aftershock alignment at each depth (a-i). White circles denote the relocated events within $0.5 \mathrm{~km}$ of each depth slice. White star denotes the epicenter of the 2000 Tottori earthquake determined by JMA. White arrows indicate a thin, low-velocity band that lies subparallel to the alignment of the majority of the aftershocks. j Horizontal grid used in the tomography (0.5 km spacing). 

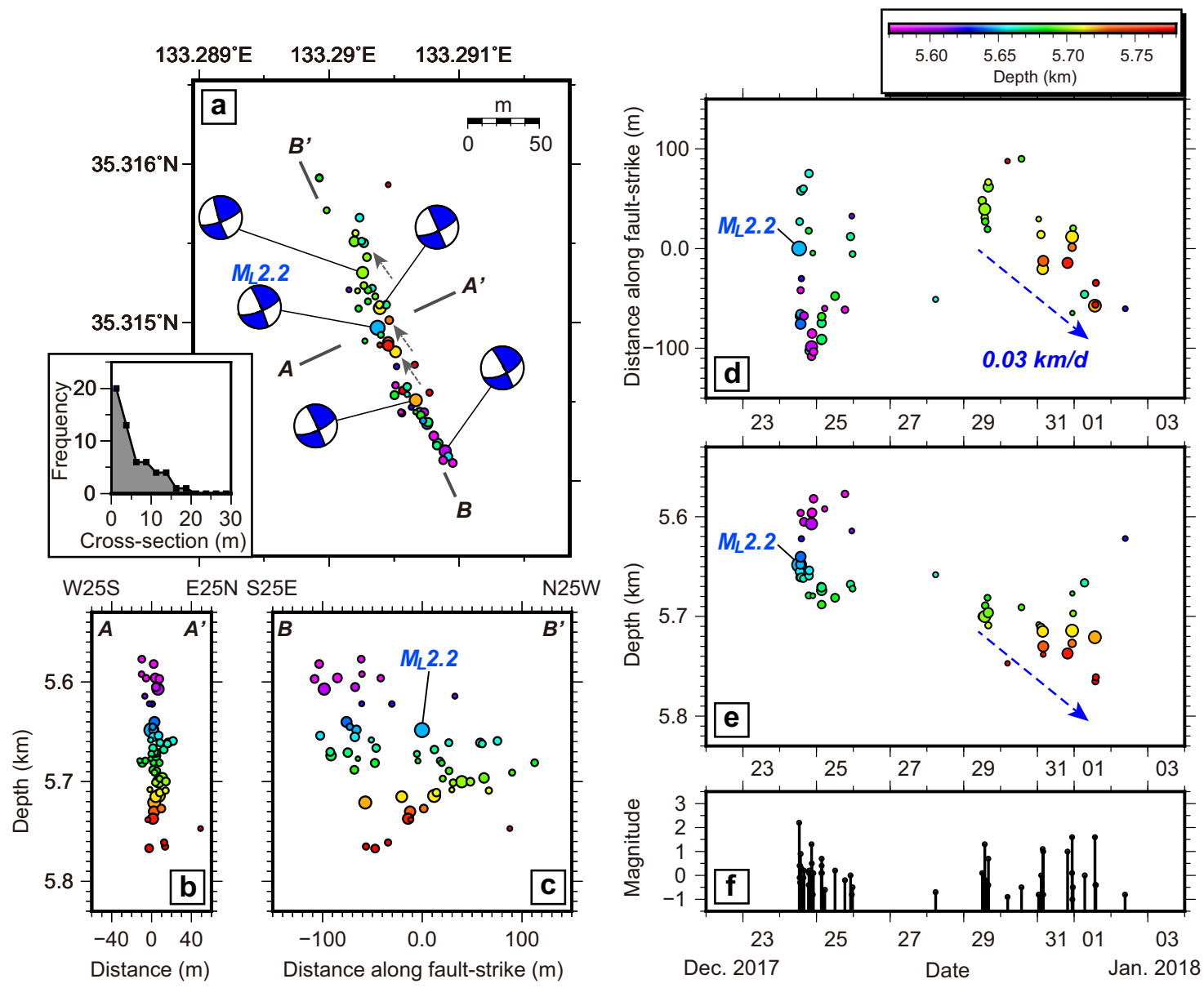

Fig. 4 Geometry and spatio-temporal evolution of a tiny seismic cluster. a Map view of the relocated events boosted by a $M_{\llcorner} 2.2$ event. The relocated hypocenters are shown as circles that are scaled to earthquake magnitude and colored to hypocentral depth. Blue beach-balls denote focal mechanisms determined by P-wave polarity data for events with $M_{\mathrm{L}}$ greater than 1.3 (Supplementary Fig. S7). Gray arrows show a possible Riedel shear structure. The inset shows a frequency distribution of the hypocenters as a function of the distance perpendicular to the fault-strike. $\mathbf{b}$, $\mathbf{c}$ Depth sections of the relocated events perpendicular and parallel to the fault-strike, respectively. $\mathbf{d}-\mathbf{f}$ Space-time diagram and an $M-T$ diagram of the relocated events associated with the $M_{\mathrm{L}} 2.2$ event, respectively.

recognized a weak bifurcation geometry in the aftershocks at depths between 4 and $6 \mathrm{~km}$ (broken lines along the slice 02 in Fig. 2b). In terms of velocity structure, the southeast end of the aftershock area is located in a relatively low-velocity body for each of the studied depth intervals, except for the depths of 3, 4, and $10 \mathrm{~km}$ (Fig. 3 and Supplementary Figs. S2-S6).

In the central fault section there is a thin, low-velocity band that lies subparallel to the alignment of the majority of the aftershocks. This low-velocity band is offset by $\sim 3 \mathrm{~km}$ to the west, as indicated by the white arrows in Fig. 3. A similar low-velocity band can still be recognized at a spatial grid spacing of $1 \mathrm{~km}$ (Supplementary Fig. S3), albeit less clearly than the band in Fig. 3. The horizontal and vertical dimensions of this low-velocity band are $\sim 5 \mathrm{~km}$ and $\sim 3 \mathrm{~km}$, respectively. No aftershocks have been detected along the low-velocity band, indicating that it may be located within a stress shadow zone produced by the 2000 Tottori earthquake ${ }^{23}$. The spatial resolution of the tomographic image is limited to $500 \mathrm{~m}$, so it is difficult to accurately image the width of the buried low-velocity band, but the width of the low-velocity band appears to be comparable to or less than $500 \mathrm{~m}$.

Spatial and temporal evolution of a tiny seismic cluster. The hyperdense seismic network of this study makes it possible to relocate micro-earthquakes accurately and to depict numerous small seismic clusters (Figs. 2 and 3). Here, we focus on a tiny seismic cluster (boosted by a $\mathrm{M}_{\mathrm{L}} 2.2$ event) near the edge of the prominent conjugate fault on the NNW side of the fault zone (a small red rectangle around the slice 19 in Fig. 2a). It has a leftlateral strike-slip focal mechanism and displays a clear lineation (Fig. 4a). Most of the relocated events at $\sim 5.65 \mathrm{~km}$ depth are aligned along a vertically dipping plane that is subparallel to the mainshock fault plane (Fig. $4 \mathrm{~b}$ ). The tiny delineated fault is $\sim 200 \mathrm{~m}$ long in the direction of strike and $150 \mathrm{~m}$ long in the direction of dip (Fig. 4c). The lineation localizes to a width of around $10 \mathrm{~m}$ (Inset in Fig. 4a), which is larger than the horizontal uncertainty ( $6.5 \mathrm{~m}$ : $95 \%$ confidence limit) of the relative hypocenter relocation (see "Methods").

The tiny seismic lineation consists of several small sub-clusters that are present in the central to northern parts of the structure (gray arrows in Fig. 4a). The fault-length of each sub-cluster is $\sim 30 \mathrm{~m}$ and the sub-clusters are separated by $\sim 15 \mathrm{~m}$ in the horizontal direction. High-accuracy focal mechanism solutions show that one of the nodal planes (NNW-SSE trend) is parallel to the direction of the major alignment (Supplementary Fig. S7). The earthquake alignment and focal mechanisms clearly indicate that this seismic sequence was macroscopically produced by leftlateral strike-slip movement.

The spatio-temporal evolution of this tiny fault zone can be used to define two sequences (Fig. $4 \mathrm{~d}-\mathrm{f}$ ): one characterized by aftershock activity immediately after the largest $M_{\mathrm{L}} 2.2$ event 
(mainshock), and another characterized by swarm-like seismicity that initiated several days after the first mainshock-aftershock sequence. Based on the distribution of the immediate aftershocks, the $M_{\mathrm{L}} 2.2$ event is inferred to have initiated near the center (Fig. 4d) and down-dip (Fig. 4e) of the rupture area. Interestingly, the second swarm-like seismicity sequence migrated along the strike of the fault toward its southeast edge, as well as in the down-dip direction. The migration distance was around $100 \mathrm{~m}$ over 4 days. Thus, the migration speed of the second sequence was $\sim 30 \mathrm{~m} / \mathrm{d}$.

\section{Discussion}

The ultra-high density of the seismic network shows that conjugate vertical lineations of relocated seismic events could be defined using very small-magnitude earthquakes (down to $\left.M_{\mathrm{L}}-0.6\right)$. Sub-vertical alignments can be identified in a crosssection along the fault-strike of the 2000 Tottori earthquake (Fig. 2c). These are interpreted to be conjugate faults related to the mainshock fault plane. Conjugate vertical faults were also observed during the 2019 Ridgecrest earthquake sequence in California $^{8}$ and the 2012 Indian Ocean earthquake ${ }^{24}$, in strikeslip stress domains. A mixed rupture of conjugate strike-slip and thrust faults was depicted during the 2018 northern Osaka earthquake, Japan ${ }^{25}$.

Most studies on the source process of the 2000 Tottori earthquake 26,27 have suggested that the largest coseismic-slip occurred around the central section (near the rupture initiation point), with a small amount of coseismic slip at both ends of the aftershock area (Fig. 2c). The central fault section at depths shallower than $6 \mathrm{~km}$ corresponds to the high-velocity body, with no obvious low-velocity fault zone visible along the aftershock lineation at $500 \mathrm{~m}$ spatial resolution $(-3<Y<6 \mathrm{~km}$ in Fig. 3), showing relatively weak aftershock activity (Fig. 2c). Thus, the 2000 Tottori mainshock must have ruptured an immature fault zone (close to intact rock), causing the largest coseismic slip to occur in the high-velocity body at depths shallower than $6 \mathrm{~km}$. Previous tomography studies have also investigated structural heterogeneities on fault planes, revealing that high-velocity features with low aftershock activity correspond to areas of large coseismic slip ${ }^{20,28,29}$. Laboratory measurements of an exhumed fault zone ${ }^{30}$ reveal that microfractures in the fluid-alteration zone are sealed leading to relatively high $\mathrm{P}$-wave velocities compared with the surrounding wall rock. Sealing of microfractures in fault zone after the dynamic rupture might contribute to postseismic recovery of seismic wave velocity, resulting to vanishing of a low-velocity damaged zone associated with the 2000 Tottori earthquake.

Even after $\sim 20$ years since the mainshock, the aftershock activity in the large-slip area has been persistently low (Fig. 2c), suggesting the potential use of micro-seismic activity as an indicator of large-slip area of historical earthquakes.

High-resolution seismic tomography has revealed a thin, lowvelocity band (the length is $\sim 5 \mathrm{~km}$ and the down-dip height is $\sim 3 \mathrm{~km}$ ) that is subparallel to the mainshock fault and is offset by $\sim 3 \mathrm{~km}$ (white arrows in Fig. 3). Low velocities can be caused by fractures filled with crustal fluids. Thus, the thin, low-velocity band is interpreted to be a blind fault zone within the brittle crust, where intense and pervasive fracturing has accumulated from previous events. This localized low-velocity feature $(<0.5 \mathrm{~km}$ wide) matches with fault zone property imaged by fault-trapped waves along several active faults, including those associated with the 1992 Landers earthquake and the 1999 Hector Mine earthquake within the eastern California shear zone in USA ${ }^{31,32}$. In contrast, the Calico fault located midway between the Landers and Hector Mine ruptures has a $\sim 1.5-\mathrm{km}$-wide low-velocity $z^{2} e^{33,34}$. Differences in the inferred widths of low-velocity zones may be due to intrinsic variations in the width of damaged zones around different faults and/or different spatial resolutions of geophysical explorations ${ }^{33}$.

The distinct low-velocity anomaly is present at the northwest side of the aftershock area. The aftershock distributions are also more complex than in the central section (Fig. 3 and Supplementary Fig. S2). Multiple conjugate faults are developed on the northwest side of the Tottori mainshock rupture area, where intense aftershocks followed the mainshock event ${ }^{35}$. The lowvelocity zone could represent developing fracture networks at the fault edge that are filled with crustal fluids. The mainshock rupture initiated in the high-velocity body at the central section, propagated to the northwest $\operatorname{side}^{27}$, and caused shear deformation in the soft volcanic rocks (low-velocity zone), resulting to the development of the conjugate faults.

We revealed the spatio-temporal migration of earthquakes in the tiny cluster both along fault-strike and down dip (Fig. 4). The migration occurred at a speed of $\sim 30 \mathrm{~m} / \mathrm{d}$, down to the deep part of the $M_{\mathrm{L}} 2.2$ source area. During the migration, each seismic subcluster was activated after the propagation front had passed. Earthquake migration is believed to be due to fluid diffusion, aseismic slow-slip transients, or a combination of the two ${ }^{36-39}$. The earthquake migration speed within the tiny seismic cluster is much slower than the typical migration speed of slow-slip events along subduction zones ${ }^{40}$. Therefore, the earthquake migration could reflect infiltration of crustal fluid into the down-dip extension of the coseismic rupture area of the $\mathrm{M}_{\mathrm{L}} 2.2$ event.

Brittle deformation associated with the $M_{\mathrm{L}} 2.2$ event could have induced a local stress concentration in the deep parts of the fault, facilitating the development of fractures. Crustal fluid might have infiltrated these fractures and triggered the migrating seismicity ${ }^{41}$. In addition, cascading ruptures for which small earthquakes trigger each other by stress transfer could play a role to induce the earthquake migration ${ }^{42}$. However, cascading ruptures may be less important as far as we assume a plausible range of static stress drop, as each migrating earthquake is not located at the edge of the rupture zone of the previous event (Supplementary Fig. S8).

Diffusional earthquake migration has been observed in fluidinduced earthquake experiments ${ }^{36}$, during tectonic swarm activity $^{12}$, and in active volcanic areas ${ }^{43}$. Upwelling of deep fluids into the San-in shear zone has also been implied from seismic tomography and geo-chemical analysis ${ }^{44}$.

From the center of the $M_{\mathrm{L}} 2.2$ fault to the north, three sets of sub-clusters can be recognized. Each cluster is $\sim 30 \mathrm{~m}$ long and rotates slightly counterclockwise from the main trend (gray arrows in Fig. 4a). The sub-clusters are almost parallel to each other and have a spacing of $\sim 15 \mathrm{~m}$. These stepped, subparallel faults are similar to en echelon cracks, which can be observed at the surface following a strike-slip earthquake rupture ${ }^{45}$. The orientation of the sub-cluster relative to the main fault suggests that it could be Riedel shears formed in association with leftlateral strike-slip faulting. Riedel shear structures often form at low levels of cumulative displacement. With a progressive increase in cumulative displacement, Riedel structures will organize into a dense elongate network, eventually coalescing to form a smooth mature fault zone $\mathrm{e}^{46,47}$.

The conjugate faults, potential blind fault, heterogeneous velocity structure, and Riedel shears indicate that the 2000 Tottori earthquake occurred as a part of a fault growth process in a young fault system. It appears that the fault system will develop into a mature, large-scale tectonic boundary over long time. The spatiotemporal pattern of seismic activity and the fault-slip distribution appear to be controlled by complexities within the young fault system. The smallest scale of crustal deformation that is resolved by our current seismic network $(\sim 10 \mathrm{~m})$ is approaching that of a 
geological survey. Future hyperdense seismic networks could unravel deformation across multiple length scales, with meter or sub-meter spatial resolution. This could lead to a greater understanding of ongoing strain localization in young fault systems possessing unique complexity.

\section{Methods}

Hyperdense seismic observation. We deployed 1000 temporary seismic stations in and around the source region of the 2000 Tottori earthquake from April 2017 to April 2018. The average spatial interval of the hyperdense seismic network was $\sim 1$ $\mathrm{km}$, covering the entire aftershock area (Fig. 1). Each seismic station was equipped with a short-period vertical-component sensor with a natural frequency of 2.0 or $4.5 \mathrm{~Hz}$. The waveform data were recorded continuously at a sampling rate of 100 $\mathrm{Hz}$ and was stored on an SD card in each data logger. The internal clock accuracy was maintained to within $1 \mathrm{~ms}$ by calibrating at 6-h intervals, using the GPS receiver on each data logger. Approximately 800 stations transferred continuous data every $6 \mathrm{~h}$ via mobile internet, using a SIM card installed in each data logger. The data loggers were operated by dry batteries for over 1 year. This low-powerconsumption data logger has been newly developed in cooperation with Kinkei System Corporation for the purpose of hyperdense seismic observation.
\end{abstract}

Seismic tomography analysis. To detect micro-earthquakes, we applied an automatic processing workflow (composed of phase picking and phase association) to the continuous waveform data retrieved from the hyperdense seismic network. All of the sensors were vertical components, so we focused exclusively on P-wave arrival time data. The initial hypocenter was calculated using $\mathrm{P}$-wave travel times, assuming the one-dimensional velocity structure routinely used by JMA.

To relocate the detected earthquakes and estimate velocity structure, we applied Double-difference travel-time tomography code ${ }^{48}$ to the arrival time data. The earthquakes with a sufficient number of arrival times (i.e., the number of $\mathrm{P}$-arrivals must be greater than 23; the median value of P-wave arrivals for each event is 209) and a low average residual of $\mathrm{P}$-wave travel times were then selected for the tomographic step. The total number of selected events was 4033 (Fig. 1b), which is about nine times the number of events recorded in the JMA catalog for the same period (455 events) (Supplementary Fig. S1). This is a significant improvement in the completeness of magnitude down to $M_{\mathrm{L}}-0.6$ (Fig. 1c). The number of absolute arrival times of $\mathrm{P}$-waves used for tomography analysis was 1.13 million, and the number of differential travel-time data for the catalog-picked P-waves exceeded 3.64 million. The JMA velocity model was used as the starting model for tomographic analysis (Supplementary Table S1). To obtain more precise differential $\mathrm{P}$ travel-time data, we applied the waveform cross-correlation technique for earthquake pairs with a spatial separation of less than $2 \mathrm{~km}$. We applied a two-way $4-10 \mathrm{~Hz}$ Butterworth filter to waveform data and used a $1.2 \mathrm{~s}$ window length beginning $0.6 \mathrm{~s}$ before the automatically picked arrival time. We then computed the differential travel-time for each earthquake pair to subsample precision using time domain cross-correlation. After selecting the differential $\mathrm{P}$ travel-time with cross-correlation exceeding 0.85 , we obtained a dataset of more accurate differential travel-time data that contained 8.47 million $\mathrm{P}$-wave observations.

The grid nodes for the tomography were located at $-300.0,-100.0,-20.0$, $-18.0,-16.0,-14.0,-12.0,-11.0,-10.0,-9.0,-8.0,-7.0,-6.0,-5.0,-4.0$, $-3.5,-3.0,-2.5,-2.0,-1.5,-1.0,-0.5,0.0,0.5,1.0,1.5,2.0,2.5,3.0,3.5,4.0,5.0$, $6.0,7.0,8.0,9.0,10.0,11.0,12.0,14.0,16.0,18.0,20.0,100.0$, and 300.0 on the Xaxis $(\mathrm{E} 35 \mathrm{~N}) ;-300.0,-100.0,-20.0,-18.0,-16.0,-14.0,-12.0,-11.5,-11.0$, $-10.5,-10.0,-9.5,-9.0,-8.5,-8.0,-7.5,-7.0,-6.5,-6.0,-5.5,-5.0,-4.5$, $-4.0,-3.5,-3.0,-2.5,-2.0,-1.5,-1.0,-0.5,0.0,0.5,1.0,1.5,2.0,2.5,3.0,3.5$, $4.0,4.5,5.0,5.5,6.0,6.5,7.0,7.5,8.0,8.5,9.0,9.5,10.0,10.5,11.0,11.5,12.0,14.0$, $16.0,18.0,20.0,100.0$, and 300.0 on the $Y$-axis $(\mathrm{N} 35 \mathrm{~W})$; and $-150.0,-20.0,0.0$, $1.0,2.0,3.0,4.0,5.0,6.0,7.0,8.0,9.0,10.0,12.0,15.0,20.0,80.0$, and 300.0 on the $Z$ (depth) axis (Fig. 1d). Near the mainshock failure area, the grid spacing was $0.5 \mathrm{~km}$ (Fig. 3j), which is much finer than that used in previous studies ${ }^{19}$.

We also used a velocity model estimated by ref. ${ }^{19}$ as the starting model for the tomographic analysis. However, the final velocity model does not show any significant change from the model that was inverted using the JMA velocity model as the initial model (Fig. 3). That is because the present study has used more than 20 times seismic stations and huge number of arrival time data, compared with ref. 19

Spatial resolution of the P-wave velocity model. We tested different spatial smoothing weights of $1,2,3,5,7,10,15,20,3045$, and 60 (see ref. 48 for details) to verify the robustness of the velocity model. Despite changing the spatial weights, the main features of the tomograms remained similar in areas with good ray coverage (Supplementary Figs. S5 and S6). Considering the trade-off between roughness and stabilization of the model (Supplementary Fig. S9), we chose the velocity model with a weighting of 10 for our preferred final model (Fig. 3). The root mean square of the absolute travel-time residual was reduced from $0.057 \mathrm{~s}$ to $0.022 \mathrm{~s}$ after 28 iterations.

To evaluate the spatial resolution of the final velocity model, we conducted a checkerboard resolution test. We computed synthetic travel times for a threedimensional velocity model using perturbations of $\pm 3 \%$ amplitude of the initial velocity model at each inversion grid, adding random noises uniformly distributed from $-0.025 \mathrm{~s}$ to $0.025 \mathrm{~s}$ for $\mathrm{P}$-waves. We then inverted the synthetic data using the same distribution of hypocenters and stations as the real data, starting from the initial velocity structure, and verified how well the test model is recovered (Supplementary Figs. S2 and S4). We demonstrated that P-wave velocity anomalies are well recovered in the areas where there are sufficient seismic events (Supplementary Figs. S2 and S4) and the derivative weight sum (DWS) ${ }^{49}$ values are sufficiently large. Note that the entire aftershock area is well resolved, with horizontal and vertical spatial grid intervals of $0.5 \mathrm{~km}$ and $1.0 \mathrm{~km}$, respectively, owing to the high density of seismic stations.

In order to assess the reliability of the model resolutions for the velocity anomalies described in the present study (Fig. 3), we also conducted a sensitivity (spike) test using a validation model shown in Supplementary Fig. S10a. Lowvelocity anomalies were assigned to grid nodes at the northwestern side of the mainshock epicenter ( $-4 \%$ at depths from 2 to $6 \mathrm{~km}$, and $-2 \%$ at depths from 7 to $10 \mathrm{~km}$ ). Furthermore, a thin low-velocity band of $-3 \%$ are given to grid nodes at depths from 5 to $8 \mathrm{~km}$, and a high-velocity zone with $+4 \%$ are assigned to grid nodes along the fault-strike nearby the mainshock epicenter (at depths from 2 to $10 \mathrm{~km}$ ) (Supplementary Fig. S10a). The calculation of the synthetic travel-time and the inversion method were the same as those employed for the checkerboard model resolution test. The results shown in Supplementary Fig. S10b indicate that the assumed velocity anomalies of P-wave were well recovered, although the recovery of the greater depths was weaker than that of the shallow depths. Based on these results, we consider that the presence of the velocity anomalies discussed in the present study is reliable.

Relocation of a seismic cluster associated with $\mathbf{M}_{\mathbf{L}}$ 2.2. We relocated a tiny seismic cluster, boosted by an event with $M_{\mathrm{L}} 2.2$. We used differential arrival times from the nearby seismic stations, with an epicentral distance of $8 \mathrm{~km}$ from the cluster centroid (189 stations among 1000). This seismic cluster contains 66 events that occurred from 24 December 2017 to 30 January 2018 (Fig. 4). We applied a double-difference relocation algorithm ${ }^{50}$ to differential travel times constructed by automatic picking (46 thousand $\mathrm{P}$-wave data) and waveform cross-correlation technique ( 84 thousand $\mathrm{P}$-waves with cross-correlation coefficient $\geq 0.85$ ). We used the one-dimensional velocity structure routinely employed in the JMA location procedures. To estimate the relative location uncertainties ( $95 \%$ confidence limit) in the horizontal and vertical directions, we conducted a jackknife test. After generating 300 sets of differential travel times with $80 \%$ of randomly selected catalog and cross-correlation data, we applied the same relocation algorithm to all of the resampled datasets. After removing events with relatively large location uncertainties, we finally obtained the highly accurate hypocenters of 56 events. The relative location errors ( $95 \%$ confidence limit) are estimated to be $3 \mathrm{~m}$ and $12 \mathrm{~m}$ in longitudinal and latitudinal directions, respectively, and $19 \mathrm{~m}$ vertically.

Focal mechanisms. We estimated focal mechanisms of several earthquakes with $M_{\mathrm{L}}$ greater than 1.3 included in the tiny relocated seismic cluster, boosted by the $M_{\mathrm{L}} 2.2$ event (Fig. $4 \mathrm{a}$ ), applying the HASH code ${ }^{51}$ to the first-motion polarities picked by automatic processing. The takeoff angles were computed using the onedimensional velocity structure routinely used in the JMA location procedure. The focal mechanisms have the highest grade (quality A) and are well constrained based on large number of polarity data $(>640)$. Ref. ${ }^{52}$ has discussed a non-double couple component of several focal mechanisms using waveform data retrieved by the hyperdense seismic network consisting of $\sim 1000$ seismic stations.

\section{Data availability}

All seismic data needed to evaluate the conclusions in the paper are available in the Zenodo repository, https://zenodo.org/deposit/4059423. Additional data related to this paper are available in the paper and/or the Supplementary Materials and can be requested from the authors.

\section{Code availability}

The code of the "HASH" used to determine focal mechanism can be found at https:// www.usgs.gov/software/hash-12. The code of the "hypoDD" used to relocate hypocenters can be found at https://www.usgs.gov/software/hypodd. The code of the "tomoDD" used to conduct seismic tomography with simultaneous relocation of hypocenters is available from H.Z. (email: zhang11@ustc.edu.cn) on request. We plotted figures using GMT5 (http://gmt.soest.hawaii.edu/projects/gmt). The other custom codes used in this study are available from A.K. on request.

Received: 16 June 2020; Accepted: 16 December 2020; Published online: 19 January 2021 


\section{References}

1. Scholz, C. H. The Mechanics of Earthquakes and Faulting. https://doi.org/ 10.1017/9781316681473 (2019).

2. Wesnousky, S. G. Seismological and structural evolution of strike-slip faults Nature 335, 340-343 (1988).

3. King, G. \& Nábělek, J. Role of fault bends in the initiation and termination of earthquake rupture. Science 228, 984-987 (1985).

4. Wesnousky, S. G. Predicting the endpoints of earthquake ruptures. Nature 444, 358-360 (2006)

5. Toda, S. Toggling of seismicity by the 1997 Kagoshima earthquake couplet: a demonstration of time-dependent stress transfer. J. Geophys. Res. 108, 2567 (2003).

6. Tanaka, M., Asano, K., Iwata, T. \& Kubo, H. Source rupture process of the 2011 Fukushima-ken Hamadori earthquake: How did the two subparallel faults rupture? Earth Planets Space 66, 101 (2014).

7. Hamling, I. J. et al. Complex multifault rupture during the $2016 \mathrm{Mw} 7.8$ Kaikōura earthquake, New Zealand. Science 356, eaam7194 (2017).

8. Ross, Z. E. et al. 2019 Ridgecrest earthquake sequence. Science 366, 346-351 (2019).

9. Miller, S. A. et al. Aftershocks driven by a high-pressure $\mathrm{CO} 2$ source at depth. Nature 427, 724-727 (2004)

10. Kato, A. et al. Anomalous depth dependency of the stress field in the 2007 Noto Hanto, Japan, earthquake: Potential involvement of a deep fluid reservoir. Geophys. Res. Lett. 38, L06306 (2011).

11. Kato, A. et al. Imaging the source regions of normal faulting sequences induced by the 2011 M9.0 Tohoku-Oki earthquake. Geophys. Res. Lett. 40, 273-278 (2013).

12. Yoshida, K., Saito, T., Urata, Y., Asano, Y. \& Hasegawa, A. Temporal changes in stress drop, frictional strength, and earthquake size distribution in the 2011 Yamagata-Fukushima, NE Japan, earthquake swarm, caused by fluid migration. J. Geophys. Res. Solid Earth 122, 10,379-10,397 (2017).

13. Ogata, Y., Katsura, K. \& Tanemura, M. Modelling heterogeneous space-time occurrences of earthquakes and its residual analysis. J. R. Stat. Soc. Ser. C Appl. Stat. 52, 499-509 (2003).

14. Kawanishi, R., Iio, Y., Yuyutake, Y., Shibutani, T. \& Katao, H. Local stress concentration in the seismic belt along the Japan Sea coast inferred from precise focal mechanisms: Implications for the stress accumulation process on intraplate earthquake faults. J. Geophys. Res. Solid Earth 114, B01309 (2009).

15. Nishimura, T. \& Takada, Y. San-in shear zone in southwest Japan, revealed by GNSS observations. Earth Planets Space 69, 85 (2017).

16. Okada, A. Characteristics of the active faults in the San'in district, western Japan. Act. Fault Res. 2002, 17-32 (2002).

17. Hansen, S. M. \& Schmandt, B. Automated detection and location of microseismicity at Mount St. Helens with a large-N geophone array. Geophys. Res. Lett. 42, 7390-7397 (2015).

18. Inbal, A., Ampuero, J. P. \& Clayton, R. W. Localized seismic deformation in the upper mantle revealed by dense seismic arrays. Science 354, 88-92 (2016).

19. Shibutani, T. \& Katao, H. High resolution 3-D velocity structure in the source region of the 2000 Western Tottori Earthquake in southwestern Honshu, Japan using very dense aftershock observations. Earth Planets Space 57, 825-838 (2005).

20. Kato, A., Miyatake, T. \& Hirata, N. Asperity and barriers of the 2004 MidNiigata prefecture earthquake revealed by highly dense seismic observations. Bull. Seismol. Soc. Am. 100, 298-306 (2010).

21. Kato, A. \& Igarashi, T. Regional extent of the large coseismic slip zone of the 2011 Mw 9.0 Tohoku-Oki earthquake delineated by on-fault aftershocks. Geophys. Res. Lett. 39, L1530 (2012).

22. Yukutake, Y. \& Iio, Y. Why do aftershocks occur? Relationship between mainshock rupture and aftershock sequence based on highly resolved hypocenter and focal mechanism distributions. Earth Planets Space 69, 68 (2017).

23. Di Carli, S., Voisin, C., Cotton, F. \& Semmane, F. The 2000 western Tottori (Japan) earthquake: Triggering of the largest aftershock and constraints on the slip-weakening distance. J. Geophys. Res. Solid Earth 113, B05307 (2008).

24. Meng, L. et al. Earthquake in a maze: compressional rupture branching during the 2012 Mw8.6 Sumatra earthquake. Science 337, 724-726 (2012)

25. Kato, A. \& Ueda, T. Source fault model of the 2018 M w 5.6 northern Osaka earthquake, Japan, inferred from the aftershock sequence. Earth Planets Space 71, 11 (2019)

26. Peyrat, S. \& Olsen, K. B. Nonlinear dynamic rupture inversion of the 2000 Western Tottori, Japan, earthquake. Geophys. Res. Lett. 31, L05604 (2004).

27. Semmane, F., Cotton, F. \& Campillo, M. The 2000 Tottori earthquake: A shallow earthquake with no surface rupture and slip properties controlled by depth. J. Geophys. Res. Solid Earth 110, B03306 (2005).

28. Thurber, C. et al. Three-dimensional compressional wavespeed model, earthquake relocations, and focal mechanisms for the Parkfield, California, region. Bull. Seismol. Soc. Am. 96, 38-49 (2006).

29. Liu, X. \& Zhao, D. Upper and lower plate controls on the great 2011 Tohokuoki earthquake. Sci. $A d v$. 4, eaat4396 (2018).

30. Rempe, $M$. et al. The relationship between microfracture damage and the physical properties of fault-related rocks: the Gole Larghe Fault
Zone, Italian Southern Alps. J. Geophys. Res. Solid Earth 123, 7661-7687 (2018).

31. Li, Y.-G., Vidale, J. E., Aki, K. \& Xu, F. Depth-dependent structure of the Landers fault zone from trapped waves generated by aftershocks. J. Geophys. Res. Solid Earth 105, 6237-6254 (2000).

32. Li, Y.-G., Vidale, J. E., Oglesby, D. D., Day, S. M. \& Cochran, E. Multiple-fault rupture of the M 7.1 Hector Mine, California, earthquake from fault zone trapped waves. J. Geophys. Res. Solid Earth 108, 2165 (2003).

33. Cochran, E. S. et al. Seismic and geodetic evidence for extensive, long-lived fault damage zones. Geology 37, 315-318 (2009).

34. Yang, H., Zhu, L. \& Cochran, E. S. Seismic structures of the Calico fault zone inferred from local earthquake travel time modelling. Geophys. J. Int. 186 760-770 (2011).

35. Fukuyama, E., Ellsworth, W. L., Waldhauser, F. \& Kubo, A. Detailed fault structure of the 2000 Western Tottori, Japan, earthquake sequence. Bull. Seismol. Soc. Am. 93, 1468-1478 (2003).

36. Shapiro, S. A., Rothert, E., Rath, V. \& Rindschwentner, J. Characterization of fluid transport properties of reservoirs using induced microseismicity. Geophysics 67, 212-220 (2002).

37. Peng, Z. \& Zhao, P. Migration of early aftershocks following the 2004 Parkfield earthquake. Nat. Geosci. 2, 877-881 (2009).

38. Roland, E. \& McGuire, J. J. Earthquake swarms on transform faults. Geophys J. Int. 178, 1677-1690 (2009).

39. Kato, A. et al. Propagation of slow slip leading up to the $2011 \mathrm{Mw} 9.0$ TohokuOki earthquake. Science 335, 705-708 (2012).

40. Obara, K. \& Kato, A. Connecting slowearthquakes to huge earthquakes. Science 353, 253-257 (2016).

41. Sibson, R. H. Rupturing in overpressured crust during compressional inversion-the case from NE Honshu, Japan. Tectonophysics 473, 404-416 (2009).

42. Ellsworth, W. L. \& Bulut, F. Nucleation of the 1999 Izmit earthquake by a triggered cascade of foreshocks. Nat. Geosci. 11, 531-535 (2018).

43. Yukutake, Y. et al. Fluid-induced swarm earthquake sequence revealed by precisely determined hypocenters and focal mechanisms in the 2009 activity at Hakone volcano, Japan. J. Geophys. Res. Solid Earth 116, B04308 (2011).

44. Nakajima, J. \& Hasegawa, A. Tomographic evidence for the mantle upwelling beneath southwestern Japan and its implications for arc magmatism. Earth Planet. Sci. Lett. 254, 90-105 (2007).

45. Quigley, M. et al. Surface rupture during the $2010 \mathrm{Mw} 7.1$ darfield(canterbury) earthquake: Implications for fault rupture dynamics and seismic-hazard analysis. Geology 40, 55-58 (2012)

46. Tchalenko, J. S. Similarities between shear zones of different magnitudes. Geol. Soc. Am. Bull. 81, 1625-1640 (1970).

47. Katz, Y., Weinberger, R. \& Aydin, A. Geometry and kinematic evolution of Riedel shear structures, Capitol Reef National Park, Utah. J. Struct. Geol. 26, 491-501 (2004)

48. Zhang, H. \& Thurber, C. H. Double-difference tomography: The method and its application to the Hayward Fault, California. Bull. Seismol. Soc. Am. 93, 1875-1889 (2003)

49. Thurber, Clifford, Eberhart-phillips, D. Local earthquake tomography with exible gridding. Comput. Geosci. 25, 809-818 (1999)

50. Waldhauser, F. \& Ellsworth, W. L. A Double-difference Earthquake location algorithm: Method and application to the Northern Hayward Fault, California. Bull. Seismol. Soc. Am. 90, 1353-1368 (2000).

51. Hardebeck, J. L. \& Shearer, P. M. A new method for determining first-motion focal mechanisms. Bull. Seismol. Soc. Am. 92, 2264-2276 (2002)

52. Hayashida, Y., Matsumoto, S., Iio, Y., Sakai, S. \& Kato, A. Non-double-couple microearthquakes in the focal area of the 2000 Western Tottori Earthquake (M 7.3) via hyperdense seismic observations. Geophys. Res. Lett. 47, e2019GL084841 (2020)

\section{Acknowledgements}

We deeply appreciate all members including researchers, technicians, and students who participated in and contributed to the deployment of the hyperdense seismic network. We are grateful to the residents and local governments of the Tottori, Shimane, and Okayama Prefectures for their strong support and understanding of the hyperdense seismic observations. We used the JMA earthquake catalog and waveform data from seismic stations operated by the National Research Institute for Earth Science and Disaster Prevention. This work was supported by the Grant-in-Aid for Scientific Research on Innovative Areas (KAKENHI No. 26109004) from the Ministry of Education, Culture, Sports, Science, and Technology (MEXT) of Japan. This study was also partially supported by JST CREST Grant Number JPMJCR1763.

\section{Author contributions}

A.K. carried out the data processing and seismic tomography analysis including relocation of micro-earthquakes and drafted the manuscript. A.K., S.S., S.M. and Y.I. 
managed and conducted the hyperdense seismic observation. S.S. conducted the data pre-processing. SS, SM and Y.I. helped draft the manuscript. All authors read and approved the final manuscript.

\section{Competing interests}

The authors declare no competing interests.

\section{Additional information}

Supplementary information is available for this paper at https://doi.org/10.1038/s43247020-00086-3

Correspondence and requests for materials should be addressed to A.K.

Peer review information Primary handling editor: Joe Aslin

Reprints and permission information is available at http://www.nature.com/reprints
Publisher's note Springer Nature remains neutral with regard to jurisdictional claims in published maps and institutional affiliations.

(c) Open Access This article is licensed under a Creative Commons Attribution 4.0 International License, which permits use, sharing, adaptation, distribution and reproduction in any medium or format, as long as you give appropriate credit to the original author(s) and the source, provide a link to the Creative Commons license, and indicate if changes were made. The images or other third party material in this article are included in the article's Creative Commons license, unless indicated otherwise in a credit line to the material. If material is not included in the article's Creative Commons license and your intended use is not permitted by statutory regulation or exceeds the permitted use, you will need to obtain permission directly from the copyright holder. To view a copy of this license, visit http://creativecommons.org/licenses/by/4.0/.

(C) The Author(s) 2021 